\title{
Article
}

\section{Neuroscience in Middle Schools: A Professional Development and Resource Program That Models Inquiry-based Strategies and Engages Teachers in Classroom Implementation}

\author{
Carrie MacNabb, ${ }^{*}$ Lee Schmitt, ${ }^{+\ddagger}$ Michael Michlin, ${ }^{\S}$ Ilene Harris,,${ }^{\| I I}$ Larry Thomas, ${ }^{\dagger}$ \\ David Chittendon, ${ }^{+}$Timothy J. Ebner, ${ }^{*}$ and Janet M. Dubinsky*
}

\begin{abstract}
*Department of Neuroscience, University of Minnesota, Minneapolis, MN 55455; ${ }^{\dagger}$ Science Museum of Minnesota, St. Paul, MN 55102; ${ }^{\$}$ Center for Applied Research and Educational Improvement, University of Minnesota, Minneapolis, MN 55455; and "Medical School Office of Educational Development and Research, University of Minnesota, Minneapolis, MN 55455
\end{abstract}

Submitted August 31, 2005; Revised February 7, 2006; Accepted February 26, 2006

Monitoring Editor: Sarah Elgin

\begin{abstract}
The Department of Neuroscience at the University of Minnesota and the Science Museum of Minnesota have developed and implemented a successful program for middle school (grades 5-8) science teachers and their students, called Brain Science on the Move. The overall goals have been to bring neuroscience education to underserved schools, excite students about science, improve their understanding of neuroscience, and foster partnerships between scientists and educators. The program includes BrainU, a teacher professional development institute; Explain Your Brain Assembly and Exhibit Stations, multimedia large-group presentation and hands-on activities designed to stimulate student thinking about the brain; Class Activities, in-depth inquiry-based investigations; and Brain Trunks, materials and resources related to class activities. Formal evaluation of the program indicated that teacher neuroscience knowledge, self-confidence, and use of inquiry-based strategies and neuroscience in their classrooms have increased. Participating teachers increased the time spent teaching neuroscience and devoted more time to "inquiry-based" teaching versus "lecture-based teaching." Teachers appreciated in-depth discussions of pedagogy and science and opportunities for collegial interactions with world-class researchers. Student interest in the brain and in science increased. Since attending BrainU, participating teachers have reported increased enthusiasm about teaching and have become local neuroscience experts within their school communities.
\end{abstract}

\section{INTRODUCTION}

To move beyond single exposures to neuroscience activities in presentations or museum visits and preplanned 'teacherproof' curricula, the Department of Neuroscience at the

DOI: $10.1187 /$ cbe.05-08-0109

Present addresses: ${ }^{\ddagger}$ Department of Medical Education, University of Illinois at Chicago, Chicago, IL 60612; "II Graduate School of Education, Hamline University, 1536 Hewitt Ave., St. Paul, MN 55104.

Address correspondence to: Janet M. Dubinsky (dubin001@ umn.edu).
University of Minnesota (UMN) and the Science Museum of Minnesota (SMM) have collaborated to design and implement an inquiry-based middle school neuroscience experience for both teachers and their students called Brain Science on the Move. The SMM provided expertise in training teachers in inquiry-based pedagogy and in engaging students through a polished assembly program, portable exhibits, and resources. The university provided neuroscience content crafted into hands-on activities and access to research scientists. Beyond making contemporary brain science accessible to middle school teachers and students, the program was designed to stimulate the interest of students from 
underserved schools about science and careers in science and to foster partnerships between scientists and educators. In this article, we describe the background for the development of the program in the context of other national middle school neuroscience education initiatives, we describe the various facets of the program, and we report the program evaluation results. These evaluation results indicated successful professional development in the area of neuroscience education for teacher participants and consequently improved neuroscience education for their students.

\section{BACKGROUND}

Since the inception of the Brain Awareness Week campaign in 1995 (Society for Neuroscience, 2004; Dana Foundation, 2005), the Neuroscience community of the UMN has encouraged and supported bench neuroscientists in spending time, annually, in raising public awareness concerning issues of brain health. After exploring different formats for public engagement, our Brain Awareness Week program has become a highly successful, sustainable effort in which university neuroscientists visit fourth- and fifth-grade classrooms, bringing human brains and a variety of interactive activities to illustrate brain function. The goals of the Brain Awareness Week program are to increase public awareness of issues surrounding brain health. The basic 1-h format flexibly incorporates activities illustrating the anatomy and functions of different brain areas, including testing reflexes and sensory discrimination, building models of neuronal structure and synaptic communication by using students, and answering student questions.

Despite the success of Brain Awareness Week, there were still significant gaps in teacher and student access to neuroscience education, which provided the stimulus for development of the Brain Science on the Move program. The neuroscience concepts presented often could not be fully explored within the 1-h visit. Teachers' limited knowledge of neuroscience affected their ability to provide previsit preparation or follow-up with more in-depth coverage of brain health issues. Although the schools were very appreciative of these visits at the time, we never knew whether neuroscience continued to be taught in the years after our visits. We were not able to develop long-standing partnerships with participating teachers. In sum, 1-h visits did not seem to provide a framework for supporting deeper classroom explorations of neuroscience.

In addition, during our visits, we encountered many questions from teachers who had read some of the popularized "brain-based" learning materials. Often these questions revealed teachers' desires for a more in-depth understanding of the neurosciences and indicated misunderstandings about basic neuroscience concepts. Moreover, neuroscience is a rapidly developing field, where exciting advances in brain research are regularly covered by the lay press. To understand this reported research, teachers and students needed to have a stronger foundation of neuroscience concepts.

In their academic training, teachers have had very few opportunities to study contemporary neuroscience. At UMN, undergraduate neuroscience courses are geared toward the upper-division level, building upon advanced biology and biochemistry backgrounds. These upper-level courses are unsuitable for general audiences, such as middle school teachers, who may not necessarily have advanced biology and biochemistry backgrounds. General psychology and biology courses may cover some elements of neuroscience in introductory lectures, but many teachers may not connect the implications of these few encounters with neuroscience to educational practice. Most curriculum materials readily available to teachers consisted of "how to" teach books that have scientifically abbreviated and often inaccurately simplified neuroscience concepts. For the classroom, intermediate and middle-level science textbook coverage of the brain is most commonly limited to the topic of the senses. Excellent curricular material was (and is) available at the elementary school level in the BrainLink materials (Tharp et al., 1993), and in a high school curriculum jointly developed by the National Association of Biology Teachers and the Society for Neuroscience (Bellamy and Frame, 1996), but very little of this material is aimed at middle school students. The Making Connections, Making Choices program targeted Washington state middle school students and teachers through summer institutes and school visits (Cunningham and Kunselman, 1999). Reverse science fairs have been developed as an innovative way to engage fourththrough sixth-grade students in neuroscience (Zardetto-Smith et al., 2000). The Neuroscience for Kids Web site (Chudler, 2005; Chudler et al., 2000, 2002) also provides excellent content and resource materials. Yet, teacher knowledge of these resources has been limited, and only the most adventurous teachers have been educating themselves to address neuroscience topics in their classrooms.

Middle school students are typically interested in topics related to their own lives. The National Science Education Standards recommend using topics applicable to students' real interests to engage students in learning (Center for Science Mathematics and Engineering Education, 1996). Neuroscience relates what is happening in the brain to behaviors. As such, teaching neuroscience in middle school addresses the recommendation of the Carnegie Council on Adolescent Development that middle school life sciences should be linked to adolescent health (Carnegie Council on Adolescent Development, 1989). The physical and cognitive growth and development that occurs during the middle school years makes neuroscience a relevant and interesting topic for this age student. In early adolescence, students have a greater capacity for complex thinking and are eager to discover how to fend for themselves (Jackson and Davis, 2000). A neuroscience curriculum can provide the resources and tools for students to answer questions about their own ability to learn, about their mood swings, or about the effects of drugs. As a frontier of contemporary science, neuroscience is a topic that captures imaginations, integrates a wide array of scientific concepts, and raises challenging questions about science policy in the twenty-first century.

Students are also more apt to adapt their own learning goals and to seek challenges when they have a deeper appreciation of how they themselves learn (Dweck, 1989; Committee on Developments in the Science of Learning and Committee on Learning Research and Educational Practice, 2000; http://www.nap.edu). Providing teachers and students with an understanding of the synapse as the biological basis of learning and memory, and how the brain changes as learning occurs, should motivate student learning across 
disciplines. We sought a way to increase teacher content knowledge in neuroscience, so that they could effectively convey the excitement of contemporary neuroscience to their students (Cameron and Chudler, 2003).

Although Minnesota students performed well on the 1999 Third International Mathematics and Science Study (TIMSS) science exam, contextually, fourth-grade science teaching was not connected to students' lives (MN TIMSS, 1998). In 1996 and 2000, 39\% of American eighth graders failed to achieve a basic level of science proficiency (National Center for Education Statistics, 2001). Most importantly, in the 1998 TIMSS study, the performance of U.S. students declined from fourth to eighth grade, relative to similar-aged students in other countries (Schmidt and McKnight, 1998; National Center for Education Statistics, 2001), despite the call for middle school educational reform a decade earlier (Carnegie Council on Adolescent Development, 1989). Thus, both locally and nationally, science classrooms need relevant curriculum content in contexts that would motivate middle school learners. What better way to engage middle school students in science than to explore the basis for their own thinking and learning processes? We hoped that by exploring our current scientific understanding of the human nervous system and the learning process with middle school students, we might encourage them to become more engaged in science.

Thus, we began to plan a comprehensive, multifaceted program to include professional development, inquiry strategies, classroom resources, and a school outreach component to increase and support teacher content knowledge and classroom implementation. The program would apply national and state standards on inquiry-based learning to the neuroscience curricular components and the teacher professional development component.

We surveyed 170 Minnesota fifth- through eighth-grade teachers by mail, to assess their need and interest in learning neuroscience and in applying it in their classroom. Of the 59 responses, $77 \%$ of the teachers had an undergraduate degree in life science or biology. A broad range of science teaching experience was represented; $20 \%$ of respondents had $1-5 \mathrm{yr}$ of experience and $26 \%$ had more than $21 \mathrm{yr}$ of experience. Forty-two percent of respondents had taken a continuing education course emphasizing science teaching within the past 2 yr. Seventy-one percent had never taken a neuroscience course, whereas the remaining $29 \%$ had taken one to three courses. However, $100 \%$ of respondents rated their neuroscience content knowledge as "very low" to "moderate." Importantly, 73\% of these teachers "saw a need for training of life science teachers in neuroscience." Eighty percent stated they would benefit from this kind of training. Unfamiliarity with neuroscience had led some teachers to believe this subject was too difficult for them or their students to understand. Teachers were also concerned that neuroscience topics would not meet state standard requirements. On the contrary, we felt that the richness of contemporary neuroscience research provided an exciting, relevant media to interest students in learning about science at the same time that they learned about their own brain and how it controls the body.

Realizing that as neuroscientists, we were experts in content background but lack the experience and credentials to address issues of pedagogy, we developed a partnership with the SMM. The SMM Education Department had extensive teacher professional development experience, a statewide school outreach capacity, and a stellar reputation within the local teaching and school community. Together, we developed the Brain Science on the Move program, which combined teacher professional development in neuroscience content with inquiry-based curricular elements and instructional methods. On the needs assessment survey, as noted, 73\% of teachers "s(aw) a need for training of life science teachers in conducting inquiry-based experiences for students." Whereas $57 \%$ of respondents on the survey rated their comfort level for implementing inquiry-based activities as "high" or "very high," only 37\% indicated a comfort level of high or above in implementing inquiry at a level to meet Minnesota's Intermediate and Middle Science Standards. Similarly, only $41 \%$ of teachers were comfortable (high or above) implementing the state standards in living systems. Thus, many middle school teachers were not sufficiently comfortable teaching life sciences using inquiry-based approaches. This finding is consistent with the 1999 TIMSS study findings that Minnesota eighth-grade science teaching was heavily content based, with little emphasis on scientific inquiry (MN TIMSS, 1999). Colleagues from the SMM addressed this need and brought an emphasis on inquirybased pedagogy to the project that has been reflected in not only what we teach but in how we teach teachers. SMM educators have ensured that the program applied national and state standards on inquiry-based learning to both the curricular components and the teacher professional development (Center for Science Mathematics and Engineering Education, 1996).

A local teacher advisory board provided input and formative feedback as the program elements were designed and crafted. Interactions among all parties participating in the program have been shaped by an ongoing sharing of expertise among teachers, museum, and university staff. Long-term relationships with teachers have resulted in continued and expanded teaching of neuroscience by using hands-on approaches in multiple classrooms in both Minnesota and Wisconsin.

\section{PROGRAM DESCRIPTION}

To move beyond single exposures to neuroscience activities in the form of presentations or museum visits, scientists from the Department of Neuroscience in collaboration with SMM educators developed a program with a sequence of resources for middle school (grades 5-8) science teachers called Brain Science on the Move. The program was supported by grants from the Howard Hughes Medical Institute's Pre-College Education Program for Biomedical Research Institutions and the Minnesota Eisenhower Professional Development program. The overall goals were to 1) improve science education in the area of neuroscience; 2) excite students about science and improve their learning in the area of neuroscience; and 3) foster partnerships among urban and rural schools, local communities, and UMN scientists and researchers, and SMM educators.

Brain Science on the Move consists of the following five components: 
1. BrainU, a summer teacher professional development institute designed to provide teachers with the knowledge, confidence, teaching skills, and resources to guide an inquiry-based neuroscience curriculum for their students.

2. Explain Your Brain (EYB) Assembly, a multimedia presentation designed to stimulate student thinking and questions about the brain.

3. EYB Exhibit Stations, a series of interactive tabletop activities for student exploration.

4. Class Activities, a set of in-depth inquiry-based investigations and experiments for the classroom.

5. Brain Trunks, a set of materials and resources loaned to classrooms from the SMM.

Two additional components, in-service support for inquiry teaching and participant follow-up, helped to integrate inquiry pedagogy and to build a community of support for teaching neuroscience.

\section{BrainU}

During BrainU, teachers learned neuroscience content through inquiry-based pedagogical approaches. In addition, teachers planned how they were going to incorporate neuroscience into their individual curricula, choosing which program elements they would use and when. During the academic year after teachers' participation in BrainU, program staff from both the UMN and the SMM brought the EYB Assembly, EYB Exhibit Stations, and Brain Trunks to each teacher's school and provided up to $3 \mathrm{~d}$ of neuroscience programs and classroom support. A trained neuroscientist was hired as the UMN program staff person responsible for directing the program. Throughout the project, a teacher advisory board and participating teachers assisted with planning advice and formative evaluations. Changes were instituted in an ongoing manner to incorporate as many suggestions as possible. The first BrainU in 2000 was $1 \mathrm{wk}$ long. In response to the feedback from participants, the Minnesota Higher Education Office, and studies indicating effective professional development that changes classroom practice required more than $1 \mathrm{wk}$ per year (Corcoran et al., 1998), subsequent BrainU institutes were extended to a $2-w \mathrm{k}$ program. The longer format provided more time for consolidation and planning how to integrate neuroscience into the school year. A 1-d follow-up session was added in May, after almost a full year of classroom implementation of concepts and methods learned in the previous summer's BrainU program. At this session, participating teachers shared and reflected upon their neuroscience teaching experiences.

The six major themes addressed during BrainU were 1) macro/microstructure and function of the nervous system, 2) neural transmission and neural imaging techniques, 3) learning and memory, 4) the use of model systems (in particular Caenorhabditis elegans and Helix aspersa), 5) properties and design of inquiry-based investigations, and 6) synthesis and design of an individualized action plan for integration of neuroscience into the curriculum. Both the National and Minnesota Science Education Standards were incorporated into the course curriculum, with particular emphasis on inquiry teaching, integration of content knowledge, and modeling and discussion of inquiry-based pedagogy. Dur- ing BrainU, teachers participated in and assessed the Assembly Program and Exhibit Stations, experienced a variety of neuroscience class activities, developed their own neuroscience inquiry investigations, and explored neurosciencerelated Web resources. By modeling and use of inquiry strategies throughout BrainU, teachers experienced how they could implement an inquiry-based approach in their own classrooms, identified how activities they already did could be shifted to be more inquiry based, and learned the advantages of giving their students the opportunity to experience the scientific process.

Throughout the institute, participants interacted with more than 20 university neuroscientists to gain a sense of what "real" scientists do. Participants visited UMN neuroscience laboratories working on cellular neuroscience, sensory-motor integration, developmental cognition, magnetic resonance imaging, and event-related potentials. Discussion about inquiry pedagogy included moving beyond just "doing" activities to learning how to ask experimental questions, how to design and conduct an investigation, and how to learn content through an inquiry-based investigation. Participants networked with their colleagues and developed individual action plans to bring the available resources and activities into their classrooms in the following school year. University credit was offered to participants. In total, 44 of the 56 teachers took BrainU for graduate credit over the course of this program.

\section{EYB Assembly}

The EYB assembly introduced neuroscience to students as an exciting, diverse, scientific field relevant to their lives. The 50-min auditorium-style program has been presented to groups as large as 300 students. The assembly uses a multimedia format with a PowerPoint script; a large, lighted brain to illustrate regional neuroanatomy; an electroencephalogram (EEG) machine; and a 15- $\times$ 6-ft model synapse with electrical (chaser lights) and chemical (bubble machine) signaling. Throughout the assembly, students take part in demonstrations, both individually and as a group, to help them understand the different functions of specific areas of the brain. The assembly uses optical and auditory illusions to pique student interest, the story of Phineas Gage to introduce functional localization and contemporary imaging techniques, a bean-bag toss by a student wearing prism glasses to illustrate neural plasticity, and a model synapse to highlight the cellular basis of learning and memory. Slides illustrating the story of a patient's operation for a brain tumor and recovery highlight the impact of scientific research on people's lives.

\section{EYB Exhibit Stations}

The EYB Exhibit Stations were set up in an available classroom or instructional space at each participating teacher's school and visited by one class at a time. The exhibits are divided into three stations: 1) real brains; 2) EEG demonstration; and 3) perception, learning, and memory. Each class is divided into three groups that rotate among the stations, by using student guides to focus investigations of each station. At the real brains station, students talk informally with a neuroscientist about the real human and ani- 
mal brains on display. At the EEG station, students explore and learn how brain waves can be measured using a computer to analyze and isolate specific wave patterns in response to an individual's eyes being shut or open. At the perception, learning, and memory stations, students engage in and reflect upon eight activities with teacher guidance. These activities illustrate concepts of specialized sensory receptors; receptive fields; desensitization; relative sensitivities; sensory-motor coordination; recall by grouping; and the sensory, motor, and associative integration necessary to perform a complex task.

\section{Class Activities}

The Brain Science on the Move class activities were inquirybased lessons designed to be completed in one or two class periods (Table 1). A teacher could request to coteach a lesson with UMN staff. This coteaching only occurred with the sheep brain dissections and C. elegans investigations. Activities were aligned with both national and state standards.

\section{Brain Trunks}

Brain Trunks were loaned to participating teachers for 2 to 3 wk. Brain Trunks included classroom sets of Altered Reality glasses, nervous system slides, and other materials that supported program activities and investigations. Brain Trunks also contained CD-ROMs, Newton's Apple videos about the brain and senses, age-appropriate books about the brain, brain coloring books for reference pictures, brain molds, brain models, and Web site resource listings. In addition, the UMN developed a Flash cartoon explaining neuronal electrical activity. An operator's guide for the Brain Trunk listed and described the function of each trunk item. For teachers, the trunks helped to mitigate the barriers of preparation time, funding, and content expertise needed to bring neuroscience topics into their classrooms.

\section{In-Service Support}

As a result of discussions with our teacher advisory board and with BrainU teacher participants about their needs, interests, and scheduling constraints, we spent on average $1 \mathrm{~d}$ presenting the assembly, $1 \mathrm{~d}$ presenting the exhibits, and at least 1 additional day providing in-service support to help teachers with the class activities. For most of the teachers, having a university scientist come into their classrooms to help present the sheep brain dissection and the C. elegans activities was critical to boosting the teachers' confidence about doing these activities in their classroom. Many teachers also commented on the value of having a trained scientist in their classrooms as a role model for their students.

\section{Follow-Up Session}

After the initial BrainU in 2000, teachers expressed the need for a follow-up session to share experiences from the school year. In response, a follow-up session was organized at the SMM for a Saturday in May for the previous summer's BrainU participants. During this 1-d workshop, teachers shared their academic year experiences, often illustrated with portfolios of student work. Discussions focused on the impact of neuroscience content on student involvement in the learning process as well as on how the inquiry-based pedagogy influenced student understanding and teaching in other areas beyond neuroscience.

\section{PROGRAM OUTCOMES}

BrainU participants and their students represented a broad cross section of Minnesotans. With respect to our intended

Table 1. Classroom activities developed during the Brain Science on the Move program ${ }^{a}$

\begin{tabular}{|c|c|c|}
\hline Content & Name & Activity \\
\hline Nervous system anatomy & What's in a Brain? & Sheep brain dissection \\
\hline Microscopic neuroanatomy & What Makes the Brain Work? & $\begin{array}{l}\text { View stained neurons in slides of spinal cord and } \\
\text { brain }\end{array}$ \\
\hline Neuronal communication & Connect the Neurons & Neural transmission kinesthetic activity \\
\hline Neural control of movement & Caeno-What? & Examination of C. elegans motor behavior \\
\hline Genetic control of behavior & Mutant Worms! & Examination of C. elegans chemotaxic behavior \\
\hline $\begin{array}{l}\text { Visual influence on motor learning and neural } \\
\text { pathways }\end{array}$ & Altered Reality & $\begin{array}{l}\text { A visual-motor learning activity that uses prism } \\
\text { glasses }\end{array}$ \\
\hline Neural pathways & Motor Learning ${ }^{\mathrm{c}}$ & Understanding reaction time through card sorting \\
\hline Learning and procedural memory & Mirror Images & Learning to draw using a mirror \\
\hline Learning and declarative memory & Memory Item Game ${ }^{\mathrm{d}}$ & Ways of remembering items \\
\hline & Recency and Primacy ${ }^{\mathrm{d}}$ & Short- versus long-term memory \\
\hline & Your Incredible Memory! & Effects of practice on improving memory \\
\hline Critical elements of thinking processes & What Is Thinking? & $\begin{array}{l}\text { Discuss how to define thinking and evaluate } \\
\text { animal behaviors based upon the definition(s) }\end{array}$ \\
\hline \multicolumn{3}{|c|}{ a Available at www.brainu.org/resources or http://www2.neuroscience.umn.edu/brainscience/resources.htm } \\
\hline \multicolumn{3}{|c|}{ b Adapted from Bellamy and Frame (1996) and Pacific Science Center (2002). } \\
\hline \multicolumn{3}{|c|}{ c Adapted from Bellamy and Frame (1996). } \\
\hline \multicolumn{3}{|c|}{ d Adapted from Tharp et al. (1993) and Chudler (2005). } \\
\hline \multicolumn{3}{|c|}{ e Dunn et al. (1998). } \\
\hline
\end{tabular}


Students had a valuable experience.

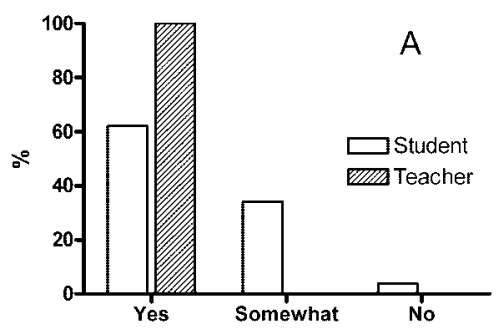

Students will take more science classes.
Students are more interested in science.

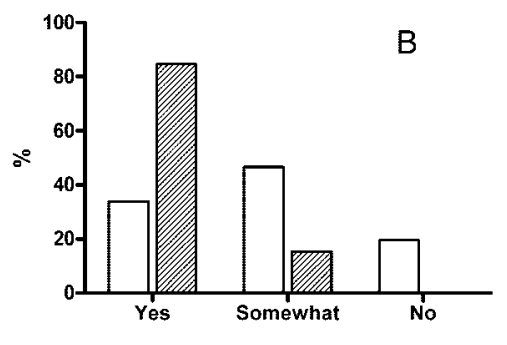

Students feel more confident in their science ability.
Figure 1. Responses of students and teachers regarding the overall value of the EYB program assessed in a classroom survey administered after completion of the EYB assembly, EYB exhibits, and teacher-directed neuroscience classroom lessons and activities. The data here and in Figures 2 and 3 are the responses of 2519 students and 39 teachers from grades 5 to 8 of 36 schools collected in 20012003.

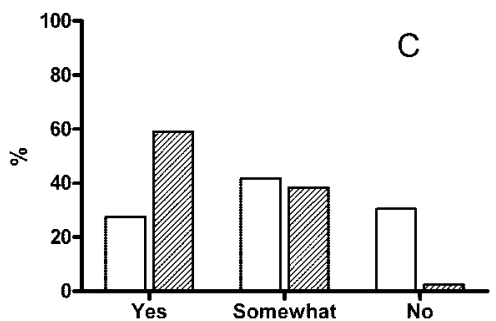

goals, we defined underserved schools as those with a high proportion of students in minority groups, in rural areas, and on free and reduced lunch. Over the course of the three BrainU institutes, 56 teachers participated in total (27 fifthsixth grade, 27 seventh-eighth grade, and 2 ninth-grade teachers). Of these teachers, 39\% represented urban, $41 \%$ suburban, and $20 \%$ rural schools. Five percent were teachers of students with special needs, and $7 \%$ were teachers of gifted students. In total, 9023 students participated in BrainU activities in these teachers' classrooms. Of these students, $49 \%$ were female, $51 \%$ male, and $31 \%$ were eligible for free and reduced lunches. Minorities made up 30\% of participating students. According to the 2000 census for Minnesota, minorities comprise $18 \%$ of the state's population under the age of 18. Thus, Brain Science on the Move reached a higher proportion of minority students than the state average, even though the rural areas contained little

Table 2. Changes in teacher content knowledge

\begin{tabular}{lcc}
\hline \multicolumn{1}{c}{ Content area } & \multicolumn{2}{c}{${\text { \% } \text { Correct }^{\text {a }}}$} \\
\hline & Pre-BU & Post-BU \\
Brain structure & 53 & 89 \\
Memory & 57 & 84 \\
Brain imaging & 47 & 84 \\
Synapse & 45 & 65 \\
Drug effects & 68 & 87 \\
Brain function & 45 & 79 \\
Learning & 86 & 100 \\
Diseases & 55 & 84 \\
Sensory/motor systems & 67 & 95 \\
Invertebrates & 49 & 98 \\
Total of knowledge items & 58 & 87 \\
\hline
\end{tabular}

${ }^{a}$ We combined data from BrainU 2001 and 2002, n = 36. Content questions and assessment were different for BrainU 2000. minority representation. Although two BrainU 2001 teachers were from small towns in rural western Wisconsin, we did not actively recruit teachers from Wisconsin nor did we consider statewide Wisconsin demographics. Overall, the program did reach underserved student populations in Minnesota.

Formal evaluations were conducted of teachers' experiences during BrainU and after teacher implementation of program elements in the following academic year. Teacher neuroscience content knowledge was evaluated using a short, multiple-choice test administered at the beginning and end of BrainU (Table 2). A pre- and post-BrainU survey that used a self-efficacy scale (Bandura, 1994) was also conducted to determine teacher confidence in their neuroscience knowledge and their perceived ability to teach neuroscience (Figures 4, 5, and 7). Additional survey items used a Likert scale (Likert, 1974) to assess the value of program elements within BrainU and teacher intentions to apply newly acquired skills and knowledge in the coming school year (Figure 8; Tables 3-5). In addition, external evaluators conducted a focus group session as the penultimate activity of each BrainU. After teachers implemented their action plans, both teachers and their students were surveyed to assess the overall impact of the entire program (Figures 1-3).

Although we gained valuable information from the evaluation, the data do have some limitations. The majority of the evaluation relies on self-reported data and is therefore subject to recall and social desirability biases. And because the teachers were self-selected participants, we have a likely selection bias as well. In an effort to keep bias to a minimum, we tried to construct survey instruments that were clear, concrete, unambiguous, and appropriately worded for teachers and middle school students, respectively, and, importantly, only presented items that asked what we needed to know to gauge our success in meeting the program goals. Because individual teachers adapted different program components in their classrooms, uniform assessment of student content knowledge across all participating classrooms was 
Altered Reality Glasses

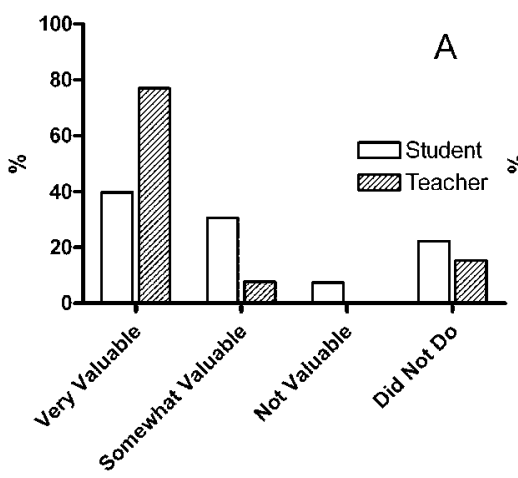

Sheep Brain Dissection

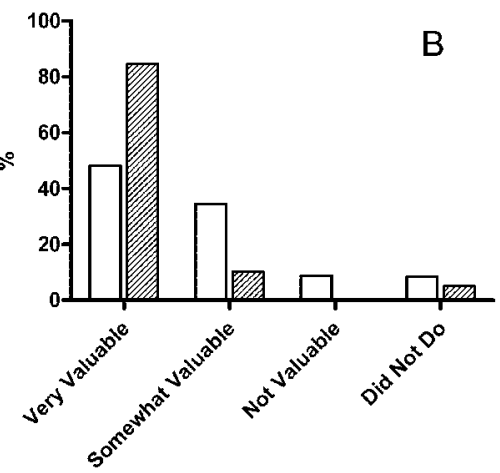

Figure 2. Responses of students and teachers to the overall value of the two most well-liked class activities.

not attempted. Teachers were informed by class performance on their own assessments when filling out the surveys. Students formulated their opinions based upon individual experiences.

\section{Overall Program Evaluation}

Overall, teachers were extraordinarily positive about the value of the EYB program and every aspect of the summer institute. Each program component was viewed as highly successful in generating enthusiasm, confidence, incorporation of inquiry-based approaches in the science classroom, and increased neuroscience knowledge of participating teachers. Both student and teacher responses on all items of the post-implementation survey were uniformly positive (Figures 1-3; not shown). All teachers viewed their partici- pation in the EYB program as worthwhile for themselves and for their students. After participating in the BrainU institute and the following EYB program in their schools, teachers reported learning more about the brain and their own teaching and learning, and they reported improvement in their students' understanding of the brain. These teachers believed that their aspirations for participating in the program had been achieved, far beyond their initial expectations. They were very positive about the educational value of each of the exhibits and activities conducted. Teachers also believed that their students had achieved the outcomes envisioned for the program.

The majority of students believed the EYB program was "worthwhile" (67\%) or "somewhat worthwhile" (29\%). Students were also positive about the value of each of the EYB exhibits and class activities (Figures 2 and 3). Moreover, they
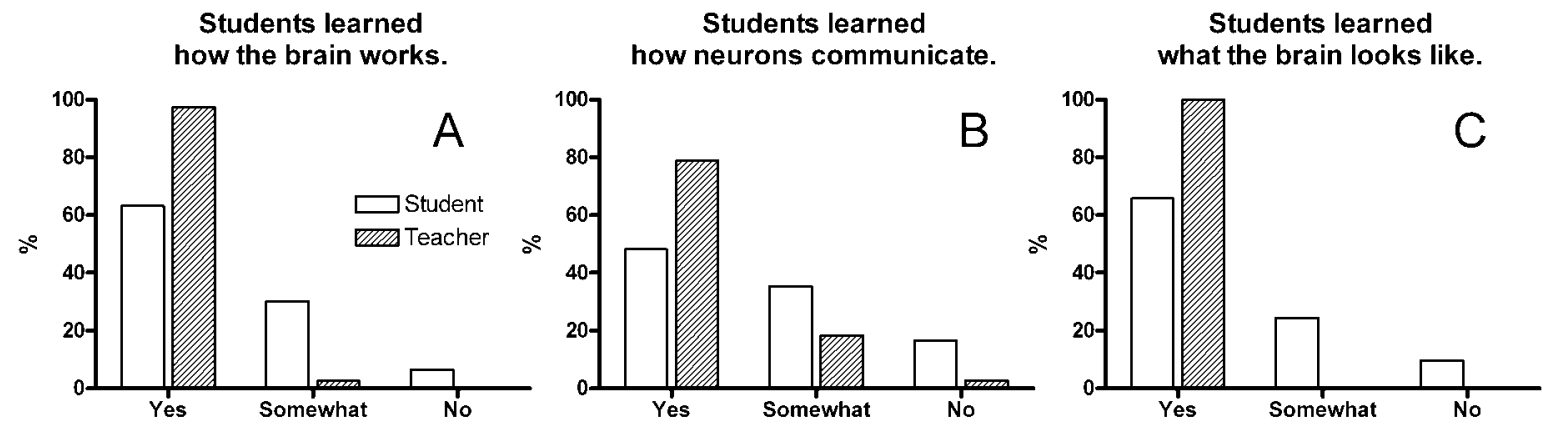

Students learned how to keep their brain healthy.

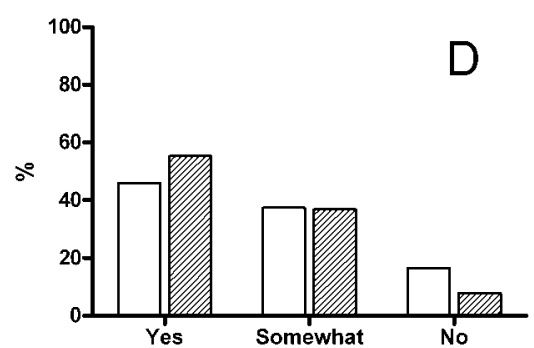

Students learned how to design and conduct an experiment.

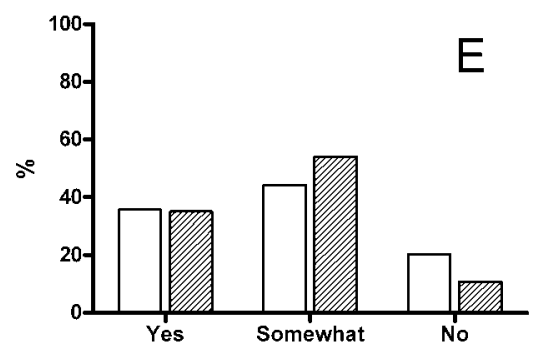

Figure 3. Assessments by students and teachers of how much was learned about specific neuroscience content, brain health, and the experimental process. 


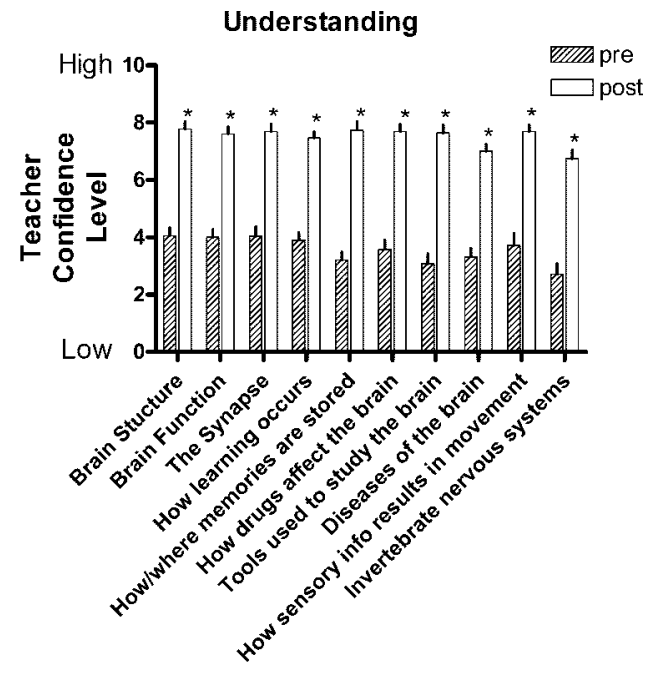

Figure 4. Changes in confidence levels of teachers' understanding of neuroscience. In the first four categories, left to right, we averaged BrainU data from three institutes, $\mathrm{n}=53$ responses. In the remaining six categories, we averaged data from BrainU 2001 and 2002, $\mathrm{n}=36$ responses. ${ }^{*} P<0.0001$ in one-tailed $t$ tests for all categories.

believed that in relation to the EYB program, a number of outcomes, detailed below, had been achieved.

\section{Improving Neuroscience Education through Increased Teacher Knowledge and Confidence}

On average, teachers' neuroscience content knowledge improved, based on results from a short, multiple-choice test

Table 3. Rated value of neuroscience content activities during BrainU

\begin{tabular}{lccc}
\hline \multicolumn{1}{c}{ Content area } & $\begin{array}{c}\text { No. } \\
\text { responding }\end{array}$ & $\begin{array}{c}\text { Mean }^{\text {rating }} \\
\text { recellent }\end{array}$ & $\begin{array}{c}\text { \% Rating } \\
\text { excelle }\end{array}$ \\
\hline Chudler Web site & 38 & 1.18 & 84 \\
Synapse & 37 & 1.19 & 84 \\
Sheep brain dissection & 52 & 1.23 & 85 \\
Brain structure and function & 43 & 1.23 & 77 \\
Learning and memory & 37 & 1.27 & 78 \\
$\quad$ activities & & & \\
C. elegans and snails & 53 & 1.28 & 72 \\
Learning and memory content & 52 & 1.30 & 77 \\
What is thinking? & 38 & 1.34 & 74 \\
Sensory and motor systems & 54 & 1.34 & 72 \\
Neuron microstructure & 52 & 1.38 & 73 \\
Brain imaging & 38 & 1.47 & 63 \\
Brains and drugs & 51 & 1.49 & 57 \\
\hline
\end{tabular}

\footnotetext{
${ }^{\text {a }}$ Variation in numbers of teachers responding reflected differences in questions asked in two or all three years of the BrainU institutes.

b 1 , highest and 5, lowest.

${ }^{\mathrm{c}}$ Includes Altered Reality inquiry investigation. Lesson plans for all activities can be found at www.brainu.org.

${ }^{d}$ Dunn et al. (1998).
}

Table 4. Rated value of science teaching activities during BrainU

\begin{tabular}{|c|c|c|c|}
\hline Content area & $\begin{array}{l}\text { No. } \\
\text { responding }\end{array}$ & $\begin{array}{l}\text { Mean } \\
\text { rating }\end{array}$ & $\begin{array}{l}\% \text { Rating } \\
\text { excellent }\end{array}$ \\
\hline Integrate inquiry methods & 38 & 1.21 & 79 \\
\hline $\begin{array}{l}\text { Design of a behavioral } \\
\text { experiment }\end{array}$ & 53 & 1.32 & 72 \\
\hline $\begin{array}{l}\text { Applications of neuroscience } \\
\text { content to teaching }\end{array}$ & 53 & 1.42 & 70 \\
\hline $\begin{array}{l}\text { Reflection/discussion time within } \\
\text { the institute }\end{array}$ & 53 & 1.55 & 64 \\
\hline $\begin{array}{l}\text { Discussion and synthesis of } \\
\text { future class designs }\end{array}$ & 53 & 1.60 & 53 \\
\hline Time to work on action plans & 38 & 1.76 & 45 \\
\hline Equity in classroom & 36 & 2.0 & 39 \\
\hline \multicolumn{4}{|c|}{$\begin{array}{l}\text { a Variation in numbers of teachers responding reflected differences } \\
\text { in questions asked in two or all three years of the BrainU institutes. } \\
\text { b } 1 \text {, highest and } 5 \text {, lowest. }\end{array}$} \\
\hline
\end{tabular}

given pre- and post-institute (Table 2). In parallel with improvements in their knowledge base, teachers' confidence in this knowledge and their ability to teach it improved, as assessed by comparing pre- and post-BrainU surveys. Across all years surveyed, BrainU produced statistically significant increases in teachers' confidence in their understanding of neuroscience (Figure 4) and in their ability to teach neuroscience (Figure 5). Moreover, in the focus group discussions, participating teachers expressed increased confidence in their own knowledge level. More specifically, misconceptions or gaps in their understanding were identified and addressed. As one teacher commented, "I feel that I have gotten a lot of excellent basic knowledge that really clarified for me some misconceptions that I have had in the past. ... it filled in a lot of blanks for me."

Teachers rated specific BrainU activities as "excellent." These activities included a guided tour from Eric Chudler's Neuroscience for Kids Web site (Chudler, 2005), activities that demonstrated key concepts about the synapse and the hands-on sheep brain dissection (Table 3). In general, the inquiry-based and hands-on activities were ranked higher than more traditionally taught activities. Activities such as those focusing on C. elegans chemotaxis and neuron micro-

Table 5. Rated value of professional development activities

\begin{tabular}{lccc}
\hline \multicolumn{1}{c}{ Content area } & $\begin{array}{c}\text { No. } \\
\text { responding }\end{array}$ & $\begin{array}{c}\text { Mean } \\
\text { rating }\end{array}$ & $\begin{array}{c}\text { \% Rating } \\
\text { excellent }\end{array}$ \\
\hline SMM visit & 35 & 1.37 & 69 \\
$\begin{array}{l}\text { Networking with university } \\
\quad \text { faculty and staff }\end{array}$ & 53 & 1.49 & 70 \\
$\begin{array}{l}\text { Networking with previous } \\
\text { BrainU teachers }\end{array}$ & 38 & 2.03 & 32 \\
\hline
\end{tabular}

a Variation in numbers of teachers responding reflected differences in questions asked in two or all three years of the BrainU institutes. b 1 , highest and 5, lowest. 


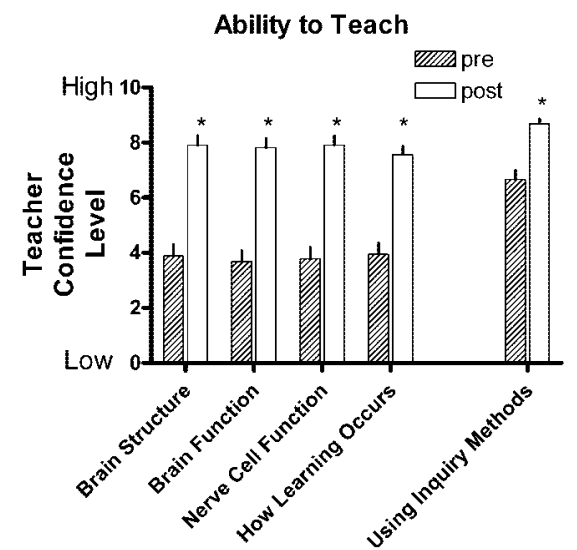

Figure 5. Changes in teachers' confidence levels in their ability to teach neuroscience. We averaged data on neuroscience content from BrainU 2001 and 2002, with $\mathrm{n}=36$, and on inquiry methods from all three institutes, with $\mathrm{n}=56$. ${ }^{*} P<0.0001$ in a one-tailed $t$ test for all categories.

structure were less highly valued by teachers because of the difficulty in set up or because teachers thought them to be less well connected to middle school students' interests than other activities. Teachers also commented that they were able to make multiple connections between neuroscience and other content areas. As a result, some teachers chose to weave neuroscience content throughout their curriculum, rather than teaching it as a stand-alone unit.

Teachers reported in the post-BrainU surveys that they valued the embedded pedagogy, although these areas were valued less highly than many of the neuroscience content activities (Table 4). Ample time and support for reflection upon teaching practices is critical for teachers trying to incorporate new approaches (Anderson and Mitchener, 1994; Borko and Putnam, 1996). Many discussions of the

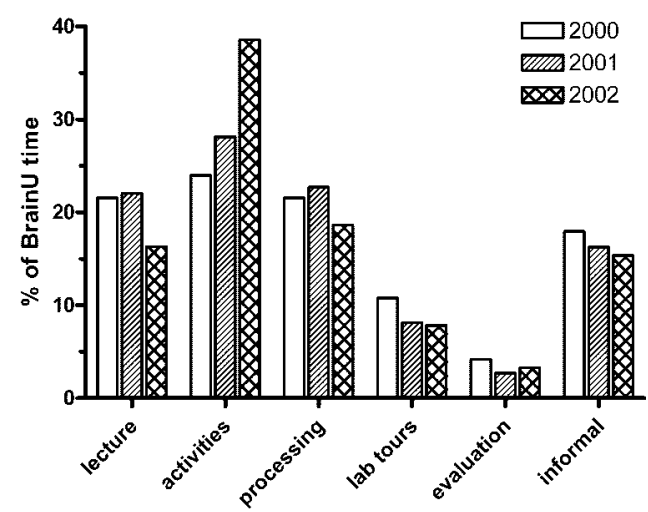

Figure 6. Time allotment for various activities during BrainU. We calculated the percentage of total contact time from printed schedules devoted to formal lectures by UMN faculty (lectures), performing classroom activities (activities), discussing pedagogical strategies used during the activities, and creating action plans (processing), touring UMN laboratories (lab tours), formal evaluation (evaluation), meals, breaks, and traveling between UMN buildings and SMM (informal).

\section{Time Teaching "The Brain"}

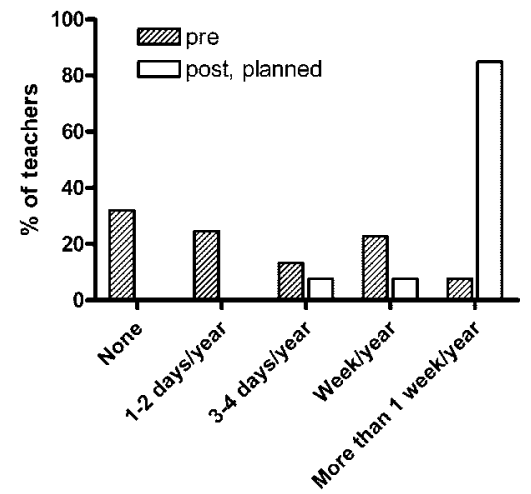

Figure 7. Amount of time teachers taught neuroscience before BrainU compared with projected amount of time to be spent teaching neuroscience after completing BrainU. We combined data from BrainU 2000, 2001, and 2002, $\mathrm{n}=53$.

pedagogy focused on examining the teaching and learning dynamics occurring during particular neuroscience activities and thus were interwoven into the activity wrap-ups. As a result, some teachers may not have identified this aspect of the institute as a specific entity in itself. A few teachers commented after BrainU 2000 that they often confused the roles of the activity leaders because sometimes the SMM facilitator taught neuroscience while discussing pedagogy and sometimes the UMN scientists modeled inquiry processes and suggested pedagogical approaches. This confusion may, indeed, have been ultimately a positive aspect of the program, in demonstrating a seamless integration of content knowledge and pedagogical methods. As one teacher commented, "Everything we did . . . we also had time to reflect and to talk about them and how you would use them, how you use them differently, and that was incredibly valuable and something that happens very seldom in workshops."

In their comments, teachers supported the relative amount of time spent during BrainU on formal content acquisition, doing classroom activities, discussing how different activities used different pedagogical approaches and planning for next year's teaching (Figure 6). We intentionally designed the agendas to reflect a balance among activities, lectures, and discussions of pedagogy. We tried to minimize the time spent in traditional lectures, consistent with modeling the instructional methods recommended for classroom implementation (Davis, 2003). Participating teachers commented favorably upon being able to experience the neuroscience investigations and inquiry first hand. Instead of a curriculum heavily weighted toward faculty lecture presentations, one faculty member served as "resident neuroscientist" to connect concepts, answer questions, and informally reinforce the neuroscience content throughout BrainU activities. Having a practicing research neuroscientist involved with the teachers for an extended period gave them opportunities to ask questions informally and interact with a neuroscientist on a more collegial basis. This personal contact provided excellent opportunities for teach- 


\section{Changes in Teaching Methods}

Lecture vs Hands-On

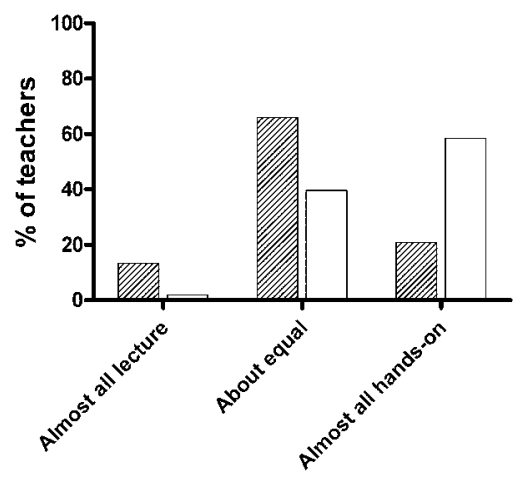

Lecture vs Inquiry

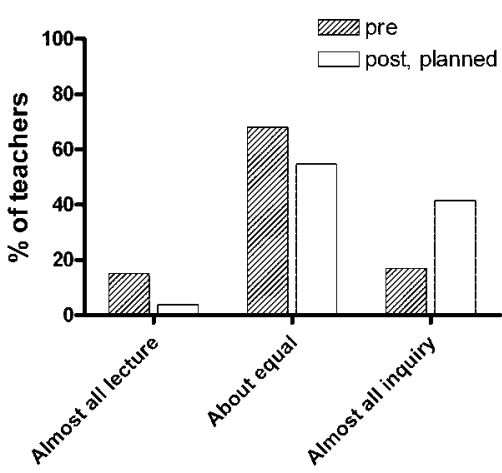

Figure 8. Changes in teaching emphasis projected by teachers after completing BrainU. We combined data from BrainU 2000, 2001, and 2002, n $=53$ respondents. ers to get to know a research scientist, something few of them had previously experienced.

Teachers reported that they planned to make changes in the amount of time spent teaching neuroscience and in the ways they teach (Figures 7 and 8). Most teachers planned to spend more than $1 \mathrm{wk}$ a year teaching neuroscience, and they also planned to shift from a more lecture-based format to more hands-on and inquiry-based methods. Some teachers also reported that they applied inquiry methodology to other content areas as well. Teacher reports during the May follow-up sessions confirmed that they were successfully able to incorporate more inquiry pedagogy into their neuroscience lessons.

According to participants, in the end-of-BrainU focus groups and in the postinstitute surveys, the benefits of BrainU were attributable to a combination of creating and modeling hands-on experiences, encouragement by the SMM educators and neuroscientists, the quality of the presentations, and having time to reflect on their experiences throughout the institute. As one teacher summarized, "What I thought was valuable was constant encouragement to learn technical material, constant connection to teaching, constant familiarization with what we would be able to do and I guess what was most important was we just didn't talk about it - we did it."

\section{Exciting Students about Science and Neuroscience}

Of the 9000 students who participated in project activities in 2001-2003, 2519 activity surveys were collected and analyzed, along with 39 completed teachers' activity surveys (of a possible 56). Student and teacher surveys were not administered immediately after the classroom neuroscience experiences were completed, but rather with variable delays depending upon individual teachers' action plans and schedules. Almost 59\% of returned students' surveys were from seventh-grade students, with the remaining portion distributed among fifth- through eighth-grade students. The results of these surveys indicated general student and teacher perspectives on students' interest in and understanding of neuroscience.

\section{Perceptions of Student Interests}

Both teachers and students reported that the students' experiences with neuroscience activities were valuable (Figure 1). Consistently throughout these data, the teachers tended to estimate a higher impact of the project and its activities on their students compared with student reports of the impact of the project and its activities (Figure 1, A-C). Possible explanations might include that the teachers were directly impacted by BrainU programming, whereas the students were one step removed from those experiences and therefore less enthusiastic about aspects of the project. The delay between completion of the neuroscience activities and survey administration may also have influenced what students remembered about the experiences. Alternatively, integration of neuroscience into other curricular elements may have altered student recognition of specific activities.

Teachers believed that their students were more interested in science, more interested in taking science courses in the future, and more confident about their abilities in science. In contrast, the largest portion of students replied that they were "somewhat" more interested in science, science courses, and more confident in their science abilities (Figure 1 , B-D). Students may have chosen somewhat over a higher level of confidence and interest out of a reluctance to overstate their actual interest. Overall, 52\% of students and 95\% of teachers indicated that the students were somewhat or definitely more interested in a career in science or medicine as a result of the EYB program. Program content, the way hands-on activities were presented, and the amount of time spent on neuroscience activities may all have contributed to the positive interest students expressed in science and medical careers.

\section{Perceptions of the Value of the Classroom Neuroscience Activities}

Both students and teachers ranked the same two activities, sheep brain dissection and Altered Reality inquiry investigation, as the most valuable for students (Figure 2). Teachers ranked the sheep brain dissection and Altered Reality inquiry among the most valuable to both themselves during BrainU (Table 3) and to their students after doing the activities in their classrooms. The popularity of these activities 
was not unexpected given that both are engaging topics, emphasizing hands-on methods in an age-appropriate context and have been included in other neuroscience curricula (Bellamy and Frame, 1996; Pacific Science Center, 2002). All the other activities were rated as "very" or "somewhat valuable" by the majority of both teachers and students. A maximum of $15 \%$ of students (for C. elegans) and $6 \%$ of teachers (for memory activities) rated an activity as "not valuable." As with the changes in interest in science (Figure 1), on all but one of the other activities, teachers valued these more than students. Although data were not collected for all activities in all years, the C. elegans activities and the neuron microstructure microscope slide exploration were performed less than other lessons (65\% of teachers did not do these lessons).

Teachers requested in-service assistance from project staff with the sheep brain dissection more than any other activity. A combination of factors may be involved. Teachers commented to staff that they enjoyed giving students exposure to real scientists in their classrooms. Teachers also wanted to have an expert on hand to field student questions regarding the activity. Although some teachers felt that the activity was important for their students to do, they did not feel comfortable preparing the materials themselves or managing the materials during the course of a full class schedule. When staff modeled teaching the dissection, teachers became more comfortable with doing the dissection and teaching it themselves.

An analysis of students' responses to the open-ended survey questions provided a more-in-depth understanding of the outcomes of the EYB program and the aspects of the program that contributed to these outcomes. Students were asked, What were the most important things you personally learned as a result of the EYB program? Of the 1308 student responses summarized from 2000 and 2001, the most frequent ones were as follows. Students learned how different parts of the brain and neurons function $(68 \%)$, how to keep your brain healthy (11\%), how the brain looks and feels (7\%), and about perception (3\%) and how important the brain is $(2 \%)$. The rest of the responses reported details of individual activities.

Students were asked, What were the best parts of the EYB program? Of the 1646 student responses, the most frequently mentioned activities were hands-on activities (36\%), Altered Reality prism glasses (16\%), sheep brain dissection $(12 \%)$, seeing and touching a real brain $(12 \%)$, and the EEG $(4 \%)$. Students also liked interacting and working on activities together (5\%), and with scientists $(4 \%)$.

Students were asked, What could be done to improve the EYB program? Their responses helped to characterize the value of the program and provided support for expansion. More than one-fourth of respondents said that there was no room for improvement (28\% of 1221 responses). Typical of these responses was the following: "Nothing could be improved because everything was great." The other most frequent comments were that students wanted more of just about everything: more activities (32\%), more time $(10 \%)$, more depth and detail $(7 \%)$, and more student interactions (2\%). Although $4 \%$ of students wanted less dissection, $1 \%$ explicitly requested more. Improvements were suggested in equipment $(3 \%)$, better instructions $(2 \%)$, more humor $(3 \%)$, and specific suggestions for individual activities (5\%). The activities drawing the most suggestions for improvement were the microscopic neuroanatomy and C. elegans activities. Both of these activities required students to use microscopes, and difficulty in using the microscopes may have contributed to their unpopularity.

\section{Perceptions of Student Learning}

In general, both teachers and students perceived that students learned how the brain works, how neurons communicate, and what a human brain looks like (Figure 3, A-C). As before, student estimates of their learning were not as great as teachers' overall assessment of what students had learned. Students may have been less confident and may have underestimated their learning. From their own in-class assessments, teachers may have been better able than students to evaluate students' learning. Alternatively, teachers may have overestimated the activities' impact on student learning due to their own increased excitement and new knowledge. In contrast to many of the responses on other questions, the same proportion of teachers (35\%) and students $(36 \%)$ agreed that students had learned more about how to design and conduct an experiment (Figure 3D). Teachers and students also agreed with one another about students learning how to keep their brains healthy (Figure 3E).

\section{Bringing Neuroscience to Minnesota Middle Schools through Building Partnerships among Teachers, $U M N$, and SMM}

Beyond the impact of the program on teachers' and students' knowledge and confidence related to neurosciences, teachers expressed the importance of networking, both with fellow teachers and with university and science museum faculty and staff (Table 5). Regular and frequent opportunities for collegial interactions among teachers and outside personnel support teacher learning and pedagogical innovation (Davis, 2003). BrainU provided this opportunity for ongoing collegial interactions. After BrainU, teachers made comments such as "Personal contacts (between) teachers and professors will aid my implementation." One of the very constructive suggestions to come from this group of teachers was to develop a means to foster these interactions in future years beyond the initial BrainU experience.

Continued interactions between teachers and UMN staff have taken many forms. Since 2000, 23\% of teachers from BrainU have traveled with UMN neuroscientists to the Annual Meeting of the Society for Neuroscience. Six of these teachers presented posters, hands-on workshops, or talks to scientist and teacher audiences at this meeting. Ten teachers have led professional development workshops for other teachers at their own schools or at regional National Science Teachers Association (NSTA) teachers' meetings. A new UMN undergraduate course, Neuroscience in the Community, is now offered at UMN. The class places undergraduate neuroscience majors in BrainU teachers' classrooms. Undergraduate students have an opportunity to explore teaching (neuro)science, and teachers have an opportunity to mentor, while exposing their students to another scientist. Six teachers have mentored undergraduate students as of spring 2005. In addition, 31 of the 56 teachers have returned for 
additional neuroscience training in follow-up programs in 2003 and 2005 (see Future Directions). Project staff remains in contact with current and previous BrainU graduates through e-mail and phone conversations, brainstorming, providing feedback, answering questions, and sharing experiences. Thus, ongoing relationships and activities involving scientists and teachers have continued well beyond the original project dates, fulfilling one of the original project goals.

\section{UNEXPECTED OUTCOMES}

In addition to achieving the goals of the grant, focus group discussions and continuing interactions among teachers and program staff testify to a number of unanticipated outcomes. Perhaps most exciting has been the development of teachers who have become local neuroscience experts within their own school communities. Many teachers report that their colleagues, families, and friends now come to them with their own brain-related questions. Teachers' professional presentations have included training their grade-level teams, district staff, and summer student classes. Teacherscientist partners have presented at regional Science Teachers Association conferences in Minnesota, Wisconsin, and NSTA meetings. One teacher has integrated neuroscience materials in an Introduction to Special Education Methods class at a local college. Teachers report that they gained prestige among their teaching peers as a result of participating in BrainU.

Laboratory tours were included as a scheduled, regular component of BrainU to illustrate the inquiry process at the professional scientific level. Additionally, teachers used the opportunity to pick up content information and to put the field of neuroscience in perspective. Most unexpectedly, several teachers commented on changes in their overall attitudes about the UMN. "Got an understanding of the research at the University I've never had before. ... I never really understood the value of the work that was being done and I have a much different attitude toward the alumni association now. Learning what a research University does." The SMM staff also developed a greater understanding of the university structure and the prominent role of research in the university's mission. The cooperation fostered between the SMM and the UMN on this project has become a model for additional SMM-UMN program partnerships.

Teachers also talked extensively about how their experiences at BrainU rekindled their enthusiasm for teaching. Teachers commented, "This week was an intellectual happy hour, more than we paid for. I came in expecting to learn, but I was so impressed by the passion and knowledge these people have. It's amazing, and I think it's good for kids to see us impassioned about what we do . . . to be superior role models. ... We had some of the top researchers, maybe, in the country. I think it's an opportunity we seldom get. It was really motivating personally."

The teaching styles of UMN program staff have been changed as a result of successive years of BrainU and teacher interactions. The teachers and SMM educators also impacted the teaching style of one resident neuroscientist. Over the course of the three BrainUs, this teacher's style shifted from direct knowledge transfer through lecturing to developing concepts as the activities unfolded and using a more inqui- ry-based approach. This transformation has carried over successfully to her undergraduate teaching, but it has not been well received in her graduate-level lectures. We consider it unfortunate that the program design did not permit more university faculty, through more extended interactions with teachers and program components, to become more reflective of their own teaching.

Special education teachers who have attended BrainU have discussed using their increased knowledge to improve their explanations of how the brain works to their students. One special education teacher now uses activities she has developed to explain autism to nonspecial education students. In a small study of her classes, she noted a $90 \%$ decrease in the number of inappropriate or negative peer interactions between her autistic and nonautistic students and a $70 \%$ increase in the number of positive interactions $(P$. Greger, unpublished observations).

\section{LESSONS LEARNED}

Over the course of this project, all staff have grown in our own knowledge of and respect for each others' specialties. Structurally, we recognized that the project's success was attributable to a dedicated central staff coordinator to run the program who was both familiar with the scientific content and a great communicator and organizer. This position was essential in leveraging and translating the university neuroscientists' knowledge to teachers. In future projects, we would argue strongly that funds dedicated to a knowledgeable central coordinator salary will be well spent. The second essential element in project design was the contribution of excellent teacher trainers whose knowledge of successful teacher professional development strategies set the tone and high standards for all teacher-scientist-staff interactions. Using inquiry-based teaching during BrainU to teach neuroscience to the teachers was critical in generating excitement about neuroscience and its relevance in middle school classrooms and in convincing teachers that inquiry methodology is effective. Throughout the planning and execution of the program, teacher input was sought, valued, and used to guide all implementation.

Content-wise, the Brain Trunks were expendable, whereas the Exhibit Stations and lesson plans were essential. Supplies provided by the program were welcomed resources, lowering one more barrier for implementation. The Assembly raised the level of importance of the curricula by giving The Brain unit school-wide publicity. Thus, the institutional and teacher partnerships brought a richness of backgrounds, creativity, and experiences to the curricula, professional training, and implementation, all contributing to programmatic success.

\section{FUTURE DIRECTIONS}

Participating teachers expressed a strong desire to expand and reinforce the neuroscience content and inquiry pedagogy they had learned in the institute. Among the participants' suggestions that emerged from the evaluation, two suggestions could not be implemented within the framework of the existing grant. The most requested addition was 
the need for additional neuroscience courses. In all $3 \mathrm{yr}$ of BrainU, teachers asked when BrainU Part 2 would be held. Some of this interest reflected the rapidly changing nature of our knowledge of brain function. Some of this interest stemmed from teachers' desire to continue their use of grant-related resources. Eighty-seven percent said an additional year of materials and resource support would be very valuable. This request may reflect how little resource support many science teachers actually have. Continued, intensive, long-term support for teachers enacting novel content and pedagogy has been designated as a critical characteristic of professional development for systemic educational change (Shields et al., 1998).

The second most common teacher suggestion was the desire to see how other teachers taught neuroscience topics in their classrooms. Seventy-four percent of survey respondents said they would be interested in both observing and being critiqued by a fellow BrainU participant. Teachers expressed interest in seeing how other teachers managed inquiry in their classrooms and in acquiring additional strategies for teaching in general and for teaching neuroscience in particular. The request to visit other classrooms, and the implicit invitation to have guest teachers in their own classroom attest to the degree of collegiality and trust developed among BrainU participants.

To try to accommodate these requests, an expanded BRAIN to Middle Schools program was developed jointly by SMM and UMN and has received National Center for Research Resources Science Education Partnership Award funding. The new program includes a 3-yr, sequential set of BrainU institutes (101, 202, and 303), which combine added neuroscience content, training in the specific inquiry strategy of questioning, and time for reflection upon teaching practices. In the academic year after BrainU 202, teacher partners will coteach neuroscience lessons in each other's classrooms. Additional inquiry-based activities have also been developed. A comprehensive evaluation plan will be used to determine whether the added years of interactions and teacher support serve to solidify teacher confidence levels to the extent that inquiry pedagogy and neuroscience content continue in their classrooms. Based upon experiences from the Brain Sciences on the Move program, the expanded project is designed to build on previous successes that one teacher summarized so clearly:

"I came with [a] cynical attitude ... What brought me here was ... that I was getting a stipend and I figured I would get current research and knowledge that, based on a lot of other workshops I'd attended, I expected [this] to be very academic. So what did I get out of it? . . I got a lot of excitement. I'm at one of those points where I'm really charged to go back into the classroom .... I got an incredible list of activities and resource[s], I got an incredible amount of knowledge on the brain, how it functions, how it works. I gained University and teacher contacts, excellent networking. I produced a plan and learned how to implement this. These are all things on a broad scale that drove that excitement."

Thus, an initial group of middle school science teachers from Minnesota and Wisconsin have enthusiastically integrated a set of engaging inquiry-based activities on a high- profile, contemporary scientific topic, understanding the human brain, into their existing science curricula. Furthermore, these teachers readily adapted inquiry-based pedagogy when neuroscience was taught in this manner. Collegial interactions among teachers, SMM staff, and UMN neuroscientists developed through both formal and informal interactions during the BrainU institutes. As a result, teachers participating in BrainU incorporated engaging neuroscience activities and inquiry strategies into their curricula and continue to serve as neuroscience resources for their community. The excitement of learning about the brain was readily shared by researchers creating new knowledge and adopted by teachers who stimulated scientific thinking and learning in students.

\section{ACKNOWLEDGMENTS}

We gratefully acknowledge the participation of UMN faculty and staff and SMM staff who participated in BrainU and provided administrative support and in-service teaching assistance over the course of the project. The success of the program reflects the enthusiastic support and participation of a large number of people from both institutions. This program received funding from the Howard Hughes Medical Foundation Grant 72500-522006, two Eisenhower Professional Development grants from the Minnesota Higher Education Office (A17496 and A32422), and the University of Minnesota's Medical School and Academic Health Center.

\section{REFERENCES}

Anderson R. D., and Mitchener C. P. (1994). Research on science teacher education. In: Handbook of Research on Science Teaching and Learning: A Project of the National Science Teachers Association, ed. D. L. Gabel, New York: Macmillan, 3-44.

Bandura, A. (1994). Self-efficacy. In: Encyclopedia of Human Behavior Volume 4, ed. V. S. Ramachaudran, New York, Academic Press, 71-81.

Bellamy, M. L., and Frame, K. (1996). Neuroscience Laboratory and Classroom Activities, National Association of Biology Teachers, Reston, VA, and the Society for Neuroscience, Washington, DC. http://www.nabt.org/sup/publications/nlca/nlca.htm (accessed 8 April 2005).

Borko, H., and Putnam, R. T. (1996). Learning to teach. In: Handbook on Educational Psychology, ed. R. C. Calfee and D. Berliner, New York: MacMillan, 673-708.

Cameron, W., and Chudler, E. (2003). A role for neuroscientists in engaging young minds. Nat. Rev. Neurosci. 4, 763-768.

Carnegie Council on Adolescent Development (1989). Turning points: preparing American youth for the 21st century. The report of the Task Force on Education of Young Adolescents, Carnegie Corporation of New York, New York, NY.

Center for Science Mathematics and Engineering Education (1996). National Science Education Standards, National Academy of Science, Washington, DC. http://www.nap.edu/openbook/ 0309053269/html/ (accessed 13 April 2006).

Chudler, E. H. (2005). Neuroscience for Kids. http:/ / faculty.washington.edu/chudler/neurok.html (accessed 7 January 2005).

Chudler, E. H., Kuwana, E. Y., Murray, M. A., and Bleeker, L. J. (2000). Neuroscience for kids: on-line and off-line activities for K-12 students and teachers. Soc. Neurosci. Abstr. 26, 41.

Chudler, E. H., Kuwana, E. Y., Murray, M. A., and Bleeker, L. J. (2002). Neuroscience for kids using a CD-ROM: evaluation of pre- 
college student neuroscience content knowledge and scientific attitudes. Soc. Neurosci. Abstr. 28, 22.37.

Committee on Developments in the Science of Learning and Committee on Learning Research and Educational Practice (2000). How People Learn. Brain, Mind, Experience and School, ed. J. D. Bransford, A. L. Brown, R. R. Cocking, M.S.B.J.D. Donovan, and J. W. Pellegrino, Washington, DC: National Academies Press.

Corcoran, T. B., Shields, P. M., and Zucker, A. A. (1998). Evaluation of NSF's Statewide Systemic Initiatives (SSI) Program. The SSIs and Professional Development for Teachers, SFI International, Menlo Park, CA. http://www.sri.com/policy/cep/mst/ssi.html (accessed 8 March 2005).

Cunningham, S. L., and Kunselman, M. M. (1999). University of Washington and partners' program to teach middle school students about neuroscience and science careers. Acad. Med. 74, 318-321.

Dana Foundation (2005). Brain Awareness Week. http:/ / www.dana. org/brainweek/ (accessed 8 March 2005).

Davis, K. S. (2003). "Change is hard": what science teachers are telling us about reform and teacher learning of innovative practices. Sci. Educ. 87, 3-30.

Dunn, T. L., Manning, J. M., Stevens, L. M., and Beck, B. B. (1998). Think Tank. A Curriculum Guide for Grades 5-12, Friends of the National Zoo, The National Zoological Park, Smithsonian Institution. http://nationalzoo.si.edu/Animals/ThinkTank/Exhibit/ default.cfm (accessed 8 April 2005).

Dweck, C. S. (1989). Motivation. In: Foundations for a Psychology of Education, ed. A. Lesgold and R. Glaser, Hillsdale, NJ: Erlbaum, 87-136.

Jackson, A. W., and Davis, G. A. (2000). Turning Points 2000. Educating adolescents in the 21st Century. A report of Carnegie Corporation of New York, Teachers College Press, Columbia University and National Middle School Association, New York, NY.
Likert, R. (1974). A method of constructing an attitude scale. In: Scaling: A Sourcebook for Behavioral Scientists, ed. G. M. Maranell, Chicago: Aldine, 233-243.

MN TIMSS (1998). Minnesota 4th Grade Results Third International Mathematics and Science Study. http://www.scimathmn.org/ timss_title.htm (accessed 8 May 2005).

MN TIMSS (1999). Minnesota 8th Grade Results Third International Mathematics and Science Study, SciMath ${ }^{\mathrm{MN}}$. http://www. scimathmn.org/timss_title.htm (accessed 8 May 2005).

National Center for Education Statistics (2001). The Nation's Report Card. National Assessment of Educational Progress (NAEP), 1996 and 2000 Science Assessments. http://nces.ed.gov/nationsreportcard/science/results/natachieve-g8.asp (accessed 8 March 2005).

Pacific Science Center (2002). Brain Power! It's all in your head. http:/ / www.pacsci.org/education/sow/brainpower/curriculum. html (accessed 8 March 2005).

Schmidt, W. H., and McKnight, C. C. (1998). Science education: what can we really learn from TIMSS? Science 282, 1830-1831.

Shields P. M., Marsh, J. A., and Adelman, N. E. (1998). Evaluation of NSF's Statewide Systemic Initiatives (SSI) Program. The SSIs' Impacts on Classroom Practice, SRI International, Menlo Park CA http://www.sri.com/policy/cep/mst/ssi.html (accessed 8 April 2005).

Society for Neuroscience (2004). BAW Report: Brain Awareness Week. Celebrating 2004, Planning for 2005. http://apu.sfn.org/ baw/bawreport2004/index.cfm (accessed 8 May 2005).

Tharp, B., Miller, L., Dresden, J., and Moreno, N. (1993). BrainLink: making the connections. Tex. Sci. Teach. 22, 10-11.

Zardetto-Smith, A. M., Mu, K., Ahmad, S. O., and Royeen, C. B. (2000). A model program for bringing neuroscience to children: an informal neuroscience education program bridges a gap. Neuroscientist $6,159-168$ 